\title{
Effect of guar gum on gastric emptying in growing pigs
}

\author{
BY ANNA L. RAINBIRD* AND A. G. LOW \\ National Institute for Research in Dairying $\dagger$, Shinfield, Reading, Berks RG2 9AT
}

(Received 15 November 1984 - Accepted 13 August 1985)

1. Simple gastric cannulas were surgically fitted to four pigs, initially of $30 \mathrm{~kg}$ live weight, to examine the effects of guar gum on gastric emptying.

2. Four semi-purified high-fat diets based on starch, casein, soya-bean oil and tallow were given to each pig. They contained 0 (control), 20, 40 or 60 g powdered guar gum $/ \mathrm{kg}$ diet. The meals as fed contained $257 \mathrm{~g}$ dry matter (DM) $/ \mathrm{kg}$.

3. The contents of the stomach were evacuated, with rinsing, before feeding or $0 \cdot 5,1,2$ or $4 \mathrm{~h}$ after feeding.

4. The mean $\mathrm{pH}$ of the digesta was unaffected by guar gum until $4 \mathrm{~h}$ after feeding when the value increased as the amount of guar gum in the diet rose.

5. The only significant effects of guar gum on the emptying of digesta and its components (compared with the control diet) were to reduce the rate of emptying of (a) digesta $1 \mathrm{~h}$ after feeding $(60 \mathrm{~g} / \mathrm{kg}$ diet $)$ and $4 \mathrm{~h}$ after feeding (40 and $60 \mathrm{~g} / \mathrm{kg}$ diets), (b) dry matter and glucose $1 \mathrm{~h}$ after feeding $(60 \mathrm{~g} / \mathrm{kg}$ diet), (c) nitrogen $1 \mathrm{~h}$ after feeding $(60 \mathrm{~g} / \mathrm{kg}$ diet) and $4 \mathrm{~h}$ after feeding (40 and $60 \mathrm{~g} / \mathrm{kg}$ diets).

6. When expressed on a half-time $\left(T_{50}\right)$ basis, the emptying of digesta and $\mathrm{N}$ (but not of DM and glucose) were significantly slower for diets containing 40 and $60 \mathrm{~g}$ guar gum $/ \mathrm{kg}$ than for the control diet.

7. The apparent viscosity of the gastric digesta ranged between 0.5 and $23.7 \%$ of the values for the diets as consumed.

8. It was concluded that the effects of guar gum on gastric emptying of high-solid meals were small, and that this was unlikely to be an important aspect of the mechanism by which guar gum reduces postprandial blood glucose concentrations.

Careful nutritional management has always been important for diabetics. Failure to maintain blood glucose levels within appropriate limits exacerbates the complications of the disease, and this is often in part the result of an unsuitable dietary composition or regimen. In recent years there has been increased emphasis on maintaining diabetics on high-carbohydrate, high-fibre diets (Jenkins et al. 1980; Simpson, 1981). In particular, slow-release or 'lente'-carbohydrate diets containing types of soluble dietary fibre which increase meal viscosity have been of interest (Jenkins \& Wolever, 1981). Various physiological properties of some types of soluble dietary fibre (for example, guar gum and pectin) have been characterized, among them their ability to reduce the peak concentration of peripheral blood glucose after a test meal (Jenkins et al. 1978). Such forms of dietary fibre are thus of great potential value for diabetics but their practical use is limited by inadequate knowledge of their effects on the digestive system and metabolism.

Among the types of dietary fibre studied by Jenkins et al. (1978), guar gum produced the greatest reduction in postprandial peripheral blood glucose concentrations. Jenkins et al. (1978) suggested that this effect might be mediated in part by a reduction in the rate of gastric emptying. Gastric emptying determines the release of dietary components for further digestion and absorption in the small intestine and this may in turn influence the time-course of metabolism. The hypothesis that a reduction in the rate of gastric emptying is an important aspect of the effect of guar gum has been confirmed in studies in man by Holt et al. (1979), Wilmshurst \& Crawley (1980) and Blackburn et al. (1984), and in rats

\footnotetext{
* Present address: Waltham Centre for Pet Nutrition, Freeby Lane, Waltham-on-the-Wolds, Melton Mowbray, Leics LE14 4RS.

$\dagger$ Now the Animal and Grassland Research Institute, Shinfield, Reading, Berks RG2 9AQ.
} 
Table 1. Composition of basal diet $(\mathrm{g} / \mathrm{kg})$

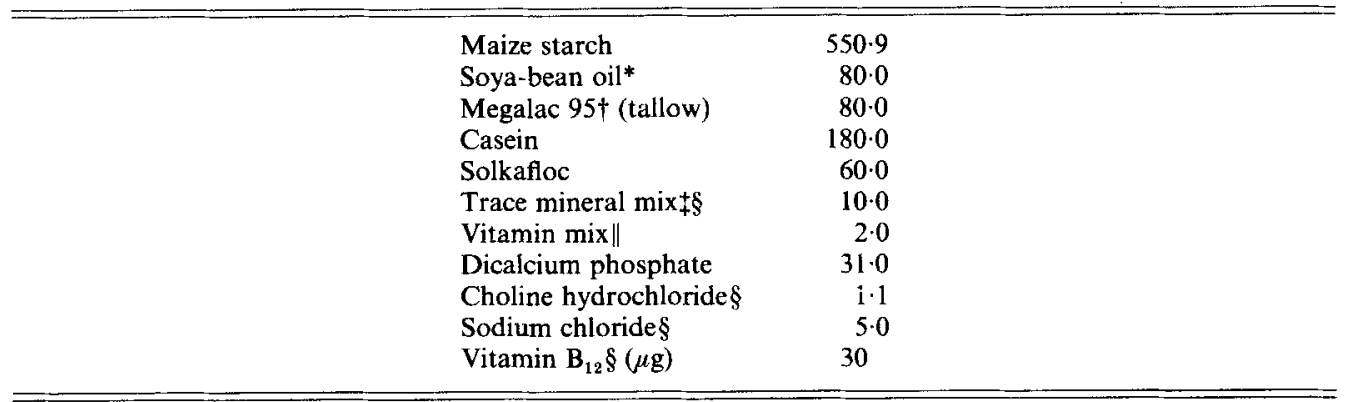

* Sainbury's soya oil; J. Sainbury Ltd, London.

$\uparrow$ Volac, Royston, Herts.

† Supplied (/kg diet): $4.47 \mathrm{~g} \mathrm{~K}_{2} \mathrm{CO}_{3}, 1 \cdot 73 \mathrm{~g} \mathrm{MgCo}_{3} \cdot \mathrm{H}_{2} \mathrm{O}, 0 \cdot 33 \mathrm{~g} \mathrm{FeSO}_{4} \cdot 7 \mathrm{H}_{2} \mathrm{O}, 80 \mathrm{mg} \mathrm{MnSO}_{4} \cdot 4 \mathrm{H}_{2} \mathrm{O}, 0 \cdot 10 \mathrm{~g}$ $\mathrm{ZnCO}_{3}, 8 \mathrm{mg} \mathrm{NaF}, 17 \cdot 5 \mathrm{mg} \mathrm{CuSO} \cdot 5 \mathrm{H}_{2} \mathrm{O}, 6 \mathrm{mg} \mathrm{CoCl}$.

$\S$ BDH Chemicals, Poole, Dorset.

|| Supplied (mg/kg diet): 12.5 retinol, 0.6 cholecalciferol, 3.25 riboflavin, 2.0 pyridoxine, $4.0 \mathrm{DL}-\alpha$-tocopheryl acetate, 5.0 biotin, 1.0 pteroylmonoglutamic acid, 195 myo-inositol, 30.0 ascorbic acid, $2 \cdot 0$ menadione, $20 \cdot 0$ $p$-aminobenzoic acid. All vitamins supplied by Roche Products Ltd, Dunstable, Beds, except myo-inositol from SAS Chemicals Lid, London and $p$-aminobenzoic acid from BDH Chemicals.

(Leeds et al. 1979). On the other hand, Jarjis et al. (1984) found no such effect in man. A feature of all these studies was the use of liquid test meals of much smaller volume and lower dry matter (DM) content than habitually eaten by man. In addition, only the emptying of the liquid phase of gastric digesta was studied, although the emptying of solids is normally of primary importance (Heading et al. 1976) because this fraction contains the starch which is the main source of glucose under normal dietary conditions.

The conflicting information available at present about the effect of guar gum on gastric emptying and in particular the lack of information on its influence when given with meals of high starch content, have led us to study this problem further, using growing pigs fitted with gastric cannulas, as a model for man. The qualitative suitability of pigs for this purpose was shown by Leeds et al. (1980) and Sambrook \& Rainbird (1985). Because viscosity has been thought to be the most important property of guar gum in modifying absorption (Jenkins et al. 1978), diets with a range of viscosities were given to pigs. Gastric emptying was measured during $4 \mathrm{~h}$ following a meal: this is the period during which peak postprandial blood glucose concentrations are found and the effect of guar gum is greatest.

The present study is one of a series on the effects of dietary fibre on gastrointestinal function in pigs, and has been published in a preliminary form by Rainbird et al. (1983). We have also demonstrated that guar gum decreases the rate of glucose absorption from the jejunum (Rainbird et al. 1984), increases nitrogen secretion in the jejunum (Low \& Rainbird, 1984), and modifies gastroduodenal motility (Rainbird, 1983). The object of these studies on the mode of action of soluble dietary fibres such as guar gum is to provide nutritional and physiological information which can ultimately be used to predict responses in clinical practice.

\section{EXPERIMENTAL METHODS}

Animals and surgery

Four male Large White $\times$ Landrace pigs of $30 \mathrm{~kg}$ initial live weight were surgically prepared with a simple gastric cannula as described by Low et al. (1985). The pigs were housed in metabolism crates throughout the experiment. 


\section{Animal weighing and feeding}

The animals were weighed weekly and fed on a scale based on their live weight. The scale used was $75 \%$ of the feeding scale described by Barber et al. (1972), i.e. the air-dry diet intake was approximately $32.5 \mathrm{~g} / \mathrm{kg}$ body-weight per $\mathrm{d}$. Each new diet and level of feeding was introduced at the evening meal on a Friday to allow $3 \mathrm{~d}$ adaptation before sampling commenced on a Monday morning. The air-dry diet was mixed with water $(1: 2.5 \mathrm{w} / \mathrm{v})$ $15 \mathrm{~min}$ before feeding and offered twice daily in equal meals at 09.00 and 17.00 hours. Guar gum was carefully sieved and mixed with an electric mixer into the diet and water to provide a virtually lump-free meal.

\section{Composition of diet}

The basal diet was a high-fat semi-purified diet, the composition of which is shown in Table 1. It was fed without or with the addition of 20, 40, or $60 \mathrm{~g}$ guar gum (Meyprogat 150; Meyhall Chemical (UK) Ltd, Wirral, Merseyside)/kg air-dry diet; when mixed with water this gave meals of the following respective viscosities: $0.071,3 \cdot 346,18 \cdot 448,32 \cdot 338 \mathrm{~N} \mathrm{~s} / \mathrm{m}^{2}$. Each pig received each of the four diets for 1 week in a Latin-square design.

\section{Collection of gastric digesta}

One sample was taken per pig per d (Monday-Friday) in a randomized order just before or $0 \cdot 5,1,2$ or $4 \mathrm{~h}$ after the morning meal. The procedure used was as described by Low et al. (1985), except that initially the majority of the digesta were evacuated undiluted, using a vacuum pump, from the stomach; this digesta was called the evacuated digesta. The stomach was then rinsed with tap water to remove any residual digesta; these were called the rinses. The total volume of the rinses did not exceed half the original gastric contents volume. After weighing and sampling, the remainder of the digesta were returned to the pig via the gastric cannula. The stomach was not rinsed out before feeding as in the study of Cuber et al. (1980) because this might alter gastric function, e.g. by removing acid which would have contributed to postprandial gastric $\mathrm{pH}$ and could have influenced the subsequent pattern of emptying.

\section{Analytical methods}

Weight of digesta. The evacuated digesta and pooled rinses were weighed to the nearest $1 \mathrm{~g}$. Weighing was considered more suitable than volume measurement because variations in the specific gravity of the digesta according to its DM content have been reported previously (Low, 1974) and guar gum caused such a large increase in the viscosity of the meal and digesta that volume measurement was impractical.

$p H$. The $\mathrm{pH}$ of well-mixed evacuated gastric digesta was measured immediately with a Pye Model $78 \mathrm{pH}$ meter fitted with a combined glass electrode.

$D M$. Duplicate 12-15 g samples of evacuated digesta and pooled rinses were dried in aluminium trays in a fan-ventilated oven for $24 \mathrm{~h}$ at $80^{\circ}$. After cooling to room temperature in a desiccator they were weighed.

Freeze-drying of digesta. Evacuated digesta and pooled rinses were freeze-dried and ground before subsequent analysis. This was done in order to obtain a thoroughly homogeneous sample from which representative small sub-samples could easily be taken for analysis.

Total $N(T N)$. This was measured in samples of approximately $0 \cdot 1 \mathrm{~g}$ freeze-dried digesta by the Kjeldahl method.

$N$ soluble in trichloroacetic acid (TCA;TCA-soluble $N)$. Approximately $5 \mathrm{~g}$ wet evacuated digesta were added to the same weight of TCA solution $(200 \mathrm{~g} / 1$; BDH Chemicals Ltd, Poole, Dorset) in a plastic centrifuge tube. After shaking they were kept at $4^{\circ}$ overnight to allow complete precipitation of TCA-insoluble N. Following centrifugation for $15 \mathrm{~min}$ 
at $1500 \mathrm{~g}$ (2500 rev./min) in an MSE Minor bench-top centrifuge (MSE Instruments, Manor Royal, Crawley, West Sussex), the supernatant fraction was stored at $-20^{\circ}$ before TN measurement by the Kjeldahl method using a $2 \mathrm{ml}$ portion.

Total glucose. Samples of approximately $0.2 \mathrm{~g}$ freeze-dried digesta were hydrolysed in $10 \mathrm{ml} 2 \mathrm{M}$-sulphuric acid for $4 \mathrm{~h}$ at $105^{\circ}$ in an oil bath to release the component monosaccharides from polysaccharides (principally glucose from starch). The hydrolysate was then filtered and made up to $25 \mathrm{ml}$ with distilled water. A $1 \mathrm{ml}$ portion of this was deproteinized using $4 \mathrm{ml}$ each of zinc sulphate $(50 \mathrm{~g} / \mathrm{l}$; BDH Chemicals Ltd) and barium hydroxide ( $51.9 \mathrm{~g} / 1$; Clintech Ltd, London). The precipitated barium sulphate was removed by centrifugation for $10 \mathrm{~min}$ at $1500 \mathrm{~g}(2500 \mathrm{rev} . / \mathrm{min})$ in an MSE Minor bench-top centrifuge. The supernatant fraction was stored at $-20^{\circ}$ for subsequent glucose analysis using an automated glucose oxidase-peroxidase method (Boehringer Mannheim, Mannheim, West Germany) on a Technicon AutoAnalyzer AAl (Technicon Instruments, Basingstoke, Hants). The percentage recovery of glucose after hydrolysis of pure starch (Merck, Darmstadt, FRG) was determined in each run.

Viscosity. The apparent viscosity of the diets and evacuated gastric digesta was measured at $25^{\circ}$ at a shear rate of $14 / \mathrm{s}$ using a Haake Rotoviscometer, Model RV3 (MSE Instruments).

\section{Expression of results}

$\mathrm{pH}$ values are direct measurements. The weights of digesta, DM, TN, and total glucose remaining in the stomach at different times after feeding are expressed as percentages of the respective intake values minus those which were found in the stomach in the pre-feed sample.

Another way of describing the gastric emptying of digesta (and its components) is to calculate the time taken for $50 \%$ of the meal to empty from the stomach. This is called the half-time or $T_{50}$ value. This was calculated from a plot of $\log$ (percentage weight of digesta or nutrient remaining in the stomach) $v$. time, for each pig and diet. The point on the straight line plot which was $\log (0.5$ initial weight) was used to denote the corresponding time-point on the abscissa, giving the $T_{50}$ value $(\mathrm{min})$. $T_{50}$ values were calculated for the emptying of digesta, DM, TN and total glucose from the stomach.

The amount of TCA-soluble $\mathrm{N}$ is expressed relative to the TN in the stomach at the same sampling time.

\section{RESULTS}

There were no problems with the surgical technique. The animals grew normally and remained in good health throughout the experiment, with no problems of leakage from the cannulas.

Recovery of DM in evacuated digesta. After feeding, most of the DM present in the stomach at a particular time was recovered in the evacuated digesta. Recovery values were lowest for the diets containing 40 and $60 \mathrm{~g}$ guar gum $/ \mathrm{kg}$. This appeared to be associated with the higher viscosity of the gastric digesta derived from these diets.

$p H$. The $\mathrm{pH}$ of the evacuated gastric digesta is shown in Fig. 1. Before feeding, the $\mathrm{pH}$ was very low but it increased from below 2 to over 5 after feeding. The $\mathrm{pH}$ then fell steadily for all diets. After $4 \mathrm{~h}$ the $\mathrm{pH}$ was significantly higher for the diets containing 40 or $60 \mathrm{~g}$ guar gum $/ \mathrm{kg}$ than for the control $(P<0.001)$.

Weight of digesta. The percentage of the diet and water intake which remained in the stomach is shown in Fig. 2. The amounts of digesta in the stomach before the morning feed were very small; they were yellow in colour and probably contained bile which had refluxed into the stomach. Only addition of $60 \mathrm{~g}$ guar gum $/ \mathrm{kg}$ significantly reduced the rate of 

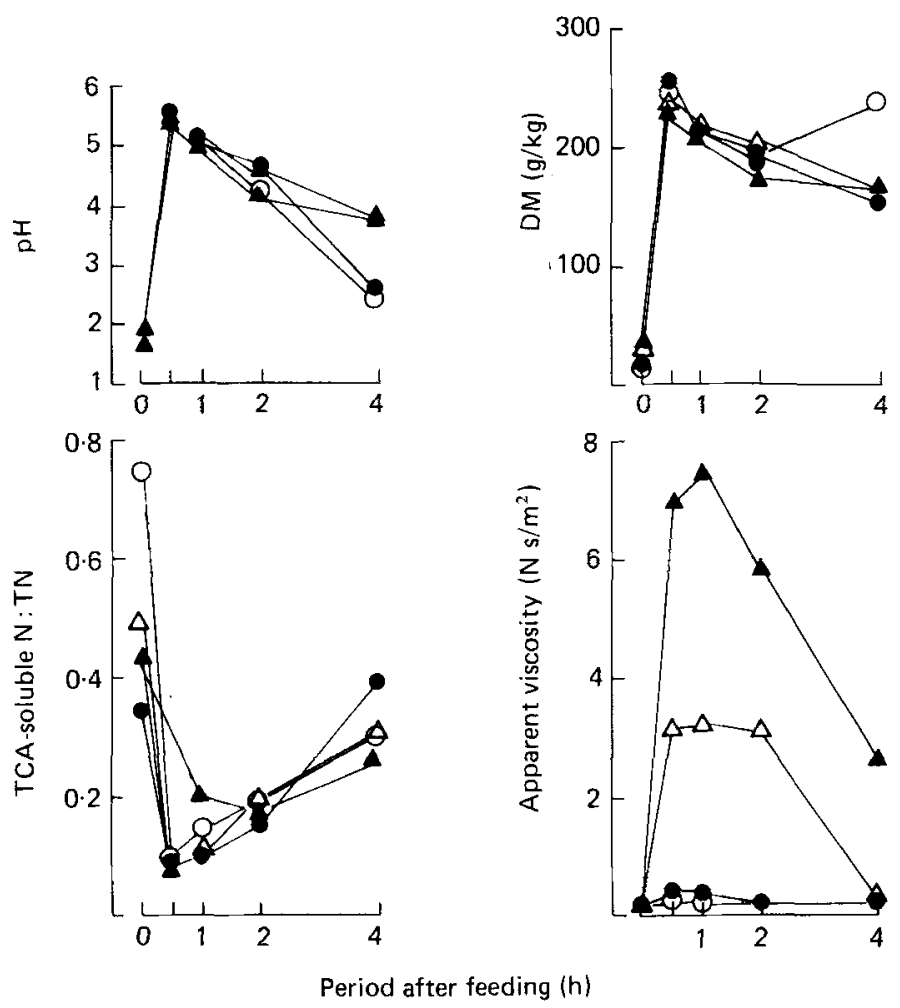

Fig. 1. Gastric pH, dry matter (DM) concentration (g/ $\mathrm{kg}$ ), trichloroacetic acid (TCA)-soluble nitrogen: total $\mathrm{N}$ and apparent viscosity of meals and evacuated gastric digesta before and $0.5,1,2$ and $4 \mathrm{~h}$ after pigs received diets without $(\bigcirc)$ or with $20 \mathrm{~g}(\odot), 40 \mathrm{~g}(\triangle)$ or $60 \mathrm{~g}(\Delta)$ guar gum $/ \mathrm{kg}$ diet.

emptying of digesta from the stomach in the first hour $(P<0.01)$, although $4 \mathrm{~h}$ after feeding there were significantly more digesta in the stomach from the 40 and $60 \mathrm{~g}$ guar gum $/ \mathrm{kg}$ diets than from the control $(P<0.01$ and $P<0.05$ respectively).

It is notable that a greater mean weight of digesta remained in the stomach $1 \mathrm{~h}$ after feeding with the 20 and $60 \mathrm{~g}$ guar gum $/ \mathrm{kg}$ diets than $0.5 \mathrm{~h}$ after feeding. This may be attributable to day-to-day variations in the rate of gastric emptying rather than to incomplete evacuation of the stomach (efficiency of evacuation was checked previously (Low et al. 1985) and was found to be very high). During the period between evacuating the stomach and returning the digesta after sampling (10-20 min), it was found that $50-100 \mathrm{ml}$ of relatively clear bile and gastric juice drained from the stomach down the PVC tubing: there was never any visible evidence of food residues being present.

$D M$. The mean percentage of the DM intake remaining in the stomach is shown in Fig. 2. There was very little DM in the stomach before the morning feed. The mean value of $6.8 \%$ for the control diet was influenced by one pig which had $23.3 \%$ of the DM intake of the previous meal in the stomach on its prefeeding sampling day whereas the other three pigs had less than $2 \%$.

It can be seen that the emptying patterns for all four diets were very similar. The only significant difference observed was $1 \mathrm{~h}$ after feeding when more of the DM intake from the meal with $60 \mathrm{~g}$ guar gum $/ \mathrm{kg}$ remained in the stomach than from the control diet. This corresponded with the greater weight of digesta observed in the stomach at this time, as mentioned previously. 

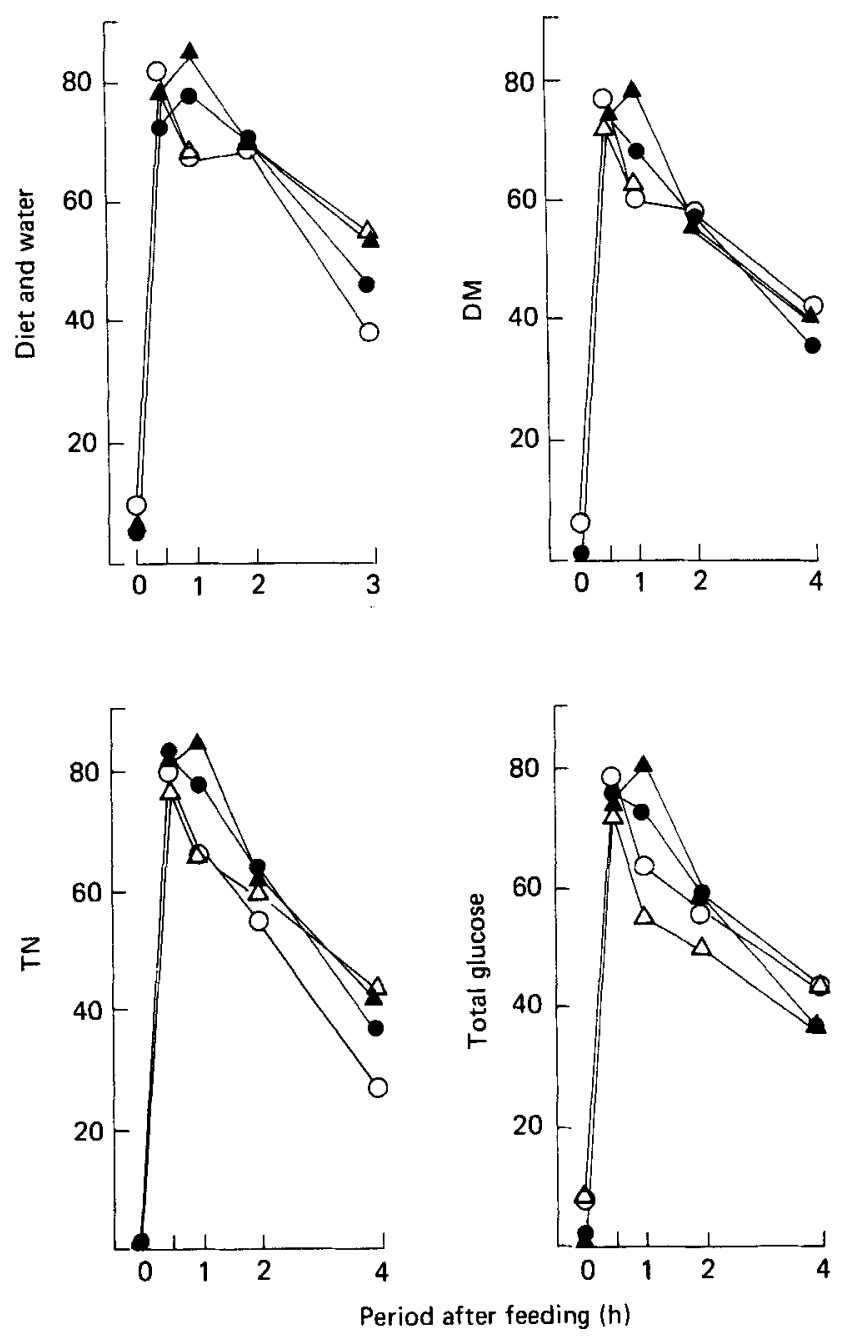

Fig. 2. Percentage of diet and water, dry matter (DM), total nitrogen (TN) and total glucose intakes remaining in the stomach before and $0.5,1,2$ and $4 \mathrm{~h}$ after pigs received diets without $(\mathrm{O})$ or with $20 \mathrm{~g}$ (O), $40 \mathrm{~g}(\triangle)$ or $60 \mathrm{~g}(\Delta)$ guar gum $/ \mathrm{kg}$ diet.

DM concentration of evacuated gastric digesta. The DM concentration of the meals and evacuated gastric digesta is shown in Fig. 1. After feeding there was a trend for the DM concentration of the digesta to fall with all diets, although the control diet showed the smallest changes. Statistical evaluation of the results was not possible as the values were the means of values from two pigs only in each case. The DM concentrations of the meals containing $0,20,40$ or $60 \mathrm{~g}$ guar gum $/ \mathrm{kg}$ were $258,260,266$ and $270 \mathrm{~g} / \mathrm{kg}$ respectively.

$T N$. The percentage of the TN intake remaining in the stomach is shown in Fig. 2. Addition of $60 \mathrm{~g}$ guar gum $/ \mathrm{kg}$ significantly $(P<0.01)$ reduced the rate of emptying of TN from the stomach and $4 \mathrm{~h}$ after feeding, compared with the control diet. At $4 \mathrm{~h}$ after feeding there was also significantly $(P<0.01)$ more TN remaining in the stomach with addition of $40 \mathrm{~g}$ guar gum $/ \mathrm{kg}$ than for the control. The patterns for the emptying of $\mathrm{TN}$ from the stomach appeared to follow those for the emptying of DM rather than digesta. 
Table 2. Half-time $\left(\mathrm{T}_{50}\right.$; min) for the emptying of digesta, dry matter, total nitrogen and total glucose from the stomach after pigs received diets containing various levels of guar gum

(Mean values with their standard errors of difference (SED) between means for four pigs)

\begin{tabular}{|c|c|c|c|c|}
\hline Diet & Digesta & Dry matter & $\begin{array}{c}\text { Total } \\
\mathrm{N}\end{array}$ & $\begin{array}{c}\text { Total } \\
\text { glucose }\end{array}$ \\
\hline Control (no guar gum) & 187 & 171 & 127 & 145 \\
\hline Guar gum $(\mathrm{g} / \mathrm{kg}): 20$ & 246 & 134 & 168 & 159 \\
\hline 40 & $309^{*}$ & 144 & $186^{*}$ & 141 \\
\hline 60 & $272^{*}$ & 160 & $185^{*}$ & 182 \\
\hline Pooled SED & $33 \cdot 2$ & $25 \cdot 8$ & $18 \cdot 6$ & 24.8 \\
\hline
\end{tabular}

Significantly different from control (in the same vertical column): ${ }^{*} P<0.05$.

$T C A$-soluble $N: T N$. The values for TCA-soluble $\mathrm{N}: T N$ (in the gastric digesta) are shown in Fig. 1. The only difference between the four diets was seen in the prefeed sample. The digesta from the control diet in the stomach before the morning feed had a significantly $(P<0.001)$ higher value than those for the other diets containing guar gum. The ratio fell $0.5 \mathrm{~h}$ after feeding but then gradually increased for all diets. The TCA-soluble $\mathrm{N}: \mathrm{TN}$ for all diets was $0 \cdot 03$.

Total glucose. The percentage of the total glucose intake remaining in the stomach is shown in Fig. 2.

The emptying of total glucose from the stomach followed a similar pattern for all four diets, the only significant $(P<0.05)$ difference being a greater amount of total glucose in the stomach $1 \mathrm{~h}$ after feeding the $60 \mathrm{~g}$ guar gum $/ \mathrm{kg}$ diet than for the control. This appeared to be associated with the greater weight of digesta and DM observed in the stomach at this time. The emptying of total glucose (primarily in the form of starch), from the stomach appeared to follow a similar pattern to the emptying of DM from the stomach.

$T_{50}$. The time taken for half the intake of food (diet and water) or of a particular nutrient to empty from the stomach is shown in Table 2. The addition of guar gum to the diet increased the mean $T_{50}$ values for digesta but this was only statistically significant for the 40 and $60 \mathrm{~g}$ guar gum $/ \mathrm{kg}$ diets. When the results were expressed in these terms guar gum appeared to reduce the rate of emptying of digesta from the stomach. However, this difference was not seen in the $T_{50}$ for the emptying of DM.

The mean $T_{50}$ for the emptying of TN from the stomach seemed to follow the pattern of DM rather than of digesta. The mean $T_{50}$ for the emptying of TN was significantly increased by the addition of 40 and $60 \mathrm{~g}$ guar gum $/ \mathrm{kg}$. On the basis of $T_{50}$ values it appeared that guar gum tended to reduce the rate of emptying of TN from the stomach.

Addition of guar gum to the diet had no effect on the mean $T_{50}$ values for the emptying of total glucose from the stomach, which appeared to follow DM emptying.

Viscosity. The effect of guar gum on the viscosity of the meal and of evacuated gastric digesta is shown in Fig. 1. Each mean value was obtained from two pigs only (each of four pigs received only two diets) because in weeks 1 and 2 the evacuated digesta and rinses were pooled immediately after sampling. Viscosity could only be measured on evacuated digesta undiluted by washings. Therefore statistical evaluation of the results has not been possible. The apparent viscosity values $\left(\mathrm{N} \mathrm{s} / \mathrm{m}^{2}\right)$ of the meals containing $0,20,40$ or 60 g guar gum $/ \mathrm{kg}$ were $0.071,3 \cdot 346,18 \cdot 448$ and $32 \cdot 338$ respectively.

It can be seen that guar gum markedly increased the viscosity of the meal. The control 
diet gave digesta of similar viscosity before and $0 \cdot 5,1,2$ and $4 \mathrm{~h}$ after feeding. Although the gastric digesta from diets containing guar gum still had a high apparent viscosity $0.5 \mathrm{~h}$ after feeding, it was much less than the viscosity of the meal eaten. Viscosity then fell steadily with time after feeding and $4 \mathrm{~h}$ later only the digesta from the diet containing $60 \mathrm{~g}$ guar $\mathrm{gum} / \mathrm{kg}$ had a higher mean viscosity than that of the control.

Standard errors of difference. The pooled SED for all comparisons of two diets at the same sampling time using the harmonic mean number of pigs per mean (3.53) was based on a pool of the main plot Latin-square error ( $6 \mathrm{df}$ ) and the subplot error ( $41 \mathrm{df})$. The SED values were: $\mathrm{pH} 0 \cdot 358$, TCA-soluble $\mathrm{N}$ : TN 0.056 , diet and water 6.4, DM 5.5, TN 5.5, total glucose $8 \cdot 7$.

\section{DISCUSSION}

Technique

The merits of gastric cannulation over duodenal re-entrant cannulation for studying the pattern of gastric emptying in pigs have been discussed in detail by Cuber et al. (1980) and Low et al. (1985). In a previous study (Low et al. 1985) all the gastric digesta were removed from the cannulated stomach by rinsing. In the present studies the majority of the digesta were removed by suction (called 'evacuated digesta') before rinsing the stomach, which allowed examination of the $\mathrm{pH}$ and $\mathrm{DM}$ content of the undiluted digesta (it was assumed that this was representative of the entire contents). The removal of digesta by suction was more complete for large volumes of digesta, and for the less-viscous diets. Rinsing the stomach out enabled us to collect all the digesta. Since each stomach was only emptied once daily and the digesta removed from the stomach were returned after weighing and sampling, the patterns of emptying of digesta from the stomach should have been normal throughout the experiment: Cuber et al. (1980) found that refeeding their pigs after the stomach had been emptied rapidly restored a normal pattern of gastric motility and emptying.

$p H$. The gastric $\mathrm{pH}$ profile after consumption of all four diets (Table 2) was generally similar to that found during gastric $\mathrm{pH}$ measurements in vivo in growing pigs given a barley-based diet (Lawrence, 1970). It also resembled that seen immediately after the meal in healthy human subjects following consumption of a sirloin-steak meal, although $\mathrm{pH}$ values had returned to basal levels $2 \mathrm{~h}$ after feeding (Fordtran \& Walsh, 1973): this may well have been related to the different types of meal, rather than to any differences between species.

The only significant effect of adding guar gum to the diet was a raised gastric $\mathrm{pH} 4 \mathrm{~h}$ after feeding (Fig. 1). There are several possible explanations for this, perhaps the most obvious being a change in acid secretion (which was, however, not measured). It is also possible that guar gum may have buffered the secreted acid. Despite the fact that acid secretion in pigs increases rapidly during the first hour after a meal (Kvasnitskii, 1951), the $\mathrm{pH}$ within the stomach remained relatively high for at least $1 \mathrm{~h}$ because the food diluted and buffered secreted acid (Malagelada et al. 1976). During the second and third hours the $\mathrm{pH}$ fell because a significant proportion of the food buffer emptied from the stomach, while gastric secretion of hydrochloric acid continued to occur.

Digesta. In the present study, very little digesta were recovered from the stomach just before the morning feed, i.e. after a $16 \mathrm{~h}$ fast (Fig. 2). This was also noted in experiments by Cuber et al. (1980) who found very little digesta in the stomach of pigs before feeding after a $24 \mathrm{~h}$ fast (i.e. one feed was given per d). By contrast, liquid test meals frequently used in human studies normally empty completely from the stomach in $2-3 \mathrm{~h}$.

The pattern of emptying of digesta (and of DM) after consumption of all four diets showed marked variability (Fig. 2), to the extent that in certain cases the mean weights of 
digesta (and DM) remaining in the stomach increased with time. This was due in part to the influence of missing values and also to variation between pigs and within pigs from day-to-day.

In general, the pattern of emptying of digesta from the stomach corresponded with that found by other authors in pigs (Zebrowska \& Buraczewska, 1972; Braude et al. 1976; Cuber \& Laplace, 1979; Cuber et al. 1980). Despite the high level of fat in the $\operatorname{diet}(160 \mathrm{~g} / \mathrm{kg})$ the rate of emptying of digesta from the stomach was higher than that reported by Cuber $e t$ al. (1980) who used a similar technique but with a semi-purified diet consisting of $(\mathrm{g} / \mathrm{kg}): 820$ starch, 150 protein supplement, 30 cellulose. Several other differences existed between the two experiments which may provide an explanation. The total meal weight and its DM concentration were not identical in the two experiments, both factors being known to alter the pattern of emptying of digesta from the stomach (Low et al. 1985). In the studies of Cuber $e t$ al. (1980) the pigs received a standard ration of $980 \mathrm{~g}$ diet mixed with 1 litre water in one meal/d whereas, in the present experiment, the pigs received the air-dry diet at $32.5 \mathrm{~g} / \mathrm{kg}$ body-weight per $\mathrm{d}$ in two equal meals, mixed with water $(1: 2 \cdot 5$, w/v $)$ before feeding.

A high initial rate of gastric emptying was observed in the first 30 min after feeding in the present study. This was much higher than the rate of emptying measured by Cuber et al. (1980) also using gastric-cannulated pigs, in which only $10 \%$ of the meal intake left the stomach in the first $30 \mathrm{~min}$. This difference is probably due to the size and DM concentration of the meals as fed, as discussed previously. Very rapid initial rates of gastric emptying have been reported, particularly when pigs with re-entrant cannulas in the proximal duodenum were given semi-purified diets. For example, Cuber \& Laplace (1979) found that in the 15 min following consumption of an identical diet to that already mentioned in the studies of Cuber et al. (1980), 33\% of the ingested meal had emptied from the stomach. However, as already pointed out by Low \& Zebrowska (1977), the opening of a duodenal re-entrant cannula disturbs the normal intraluminal pressure and this may modify the rate of gastric emptying.

Guar gum only decreased the rate of gastric emptying of digesta when it was present at concentrations of 40 and $60 \mathrm{~g}$ guar gum $/ \mathrm{kg}$ diet, suggesting that there is a threshold concentration below which effects are not seen.

In most studies on the effect of guar gum on gastric emptying only the emptying of liquids has been measured and water-soluble markers have been used (Holt et al. 1979; Wilmshurst \& Crawley, 1980; Daumerie \& Henquin, 1982; Blackburn et al. 1984; Jarjis et al. 1984). Therefore it is difficult to make direct comparisons. However, the results from the present study showing a reduction in the rate of emptying of digesta from the stomach when guar gum was added to the diet may be consistent with those of the authors mentioned previously who showed a reduction in the rate of emptying of liquids from the stomach when guar gum was added to various liquid test meals.

$D M$. The emptying of the DM components of digesta is probably of greater importance in the regulation of carbohydrate metabolism since they contain all the glucose. The pattern of emptying of DM from the stomach after the control diet (Fig. 2) was very similar to that observed by Cuber et al. (1980). This is of interest because it might be expected that the high level of fat in the diet in the present study $(160 \mathrm{~g} / \mathrm{kg})$ would lead to slower emptying of DM than observed by Cuber et al. (1980) who used a fat-free diet. Although the inhibitory effect of fat on gastric emptying is well established under conditions where low volumes of liquid test meals are given (Hunt \& Knox, 1968), it seems that fat does not play a major role in the gastric emptying of such diets as those used here. Addition of fat had minor effects on the gastric emptying of cereal-based diets in pigs (Low et al. 1985).

Addition of guar gum to the diet had no effect on the emptying of DM from the stomach 
(Table 3). Although it is technically possible to measure the emptying of DM from the stomach in humans (Heading et al. 1976), there are no studies on the effect of guar gum on gastric emptying of meals with a high DM content. However, in a study using rats, Leeds et al. (1979) did measure the $T_{50}$ for the emptying of glucose, which was the only constituent of the DM in the glucose drink used, and found an increase from 16 to $41 \mathrm{~min}$ when the viscosity of the meal was increased by guar gum. This discrepancy between the results of the present experiment using a high-fat semi-purified diet in pigs and those of Leeds $e t$ al. (1979) who gave a glucose drink $(50 \mathrm{~g} / 1)$ in rats may be related to differences in species, methods of measurement of gastric emptying or to the nature of the meal.

$D M$ concentration of evacuated digesta. The mean DM concentration of the evacuated digesta removed from the stomach by suction was higher for the control diet than for the diets containing guar gum $4 \mathrm{~h}$ after feeding (Fig. 1). This is related to the observation that guar gum reduced the rate of emptying of digesta but had no effect on the emptying of DM. Such an effect might have been due to an increase in secretion induced by guar gum but as guar gum leads to increases rather than decreases in the $\mathrm{pH}$ of gastric digesta this is perhaps not the most likely explanation. An alternative explanation is that the solid and liquid phases of the digesta emptied from the stomach at different rates in the absence of guar gum. This latter possibility is supported by the observation that the DM in the control diet rapidly settled on the bottom of a beaker once it had been thoroughly mixed with water whereas, when guar gum was added to the diet, a gel-like homogeneous meal was produced when mixed with water. Under these conditions separate rates of emptying of liquid and solid phases of digesta would be less likely to occur. A more rapid emptying of the liquid phase of digesta than of the solid phase has also been observed in human studies (e.g. Heading et al. 1976).

$T N$. The results in Fig. 2 show that the flow of TN appeared to follow the general emptying pattern of DM after all diets. Cuber et al. (1980) found a similar relation in studies with pigs given a diet based on maize starch and a protein supplement.

$T C A$-soluble $N: T N$. With all four diets the proportion of TCA-soluble $\mathrm{N}$ in the TN increased with time after feeding (Fig. 1) because of intragastric peptic hydrolysis of dietary proteins. This pattern was also noted by Cuber $e t$ al. (1980) although slightly higher values were found possibly because of differences in the protein sources used.

The lack of effect of guar gum on TCA-soluble $\mathrm{N}$ : TN suggests that guar gum did not reduce the rate of digestion of protein by pepsin in the stomach.

Total glucose. The pattern of emptying of total glucose from the stomach (Fig. 2) after the control diet corresponded with that of DM and was unaffected by guar gum. Similar observations were made in pigs, in the case of the control diet, by Cuber et al. (1980).

Viscosity. Before discussing the effect of guar gum some important points regarding the conditions of measurement of viscosity must be considered; in previous studies these have differed greatly, and have often not been fully specified. Viscosity was measured in the present study at $25^{\circ}$ and not body temperature. This is probably not of great importance because the viscosity of guar gum solutions does not vary much within this temperature range and the meal had frequently not reached body temperature in the stomach $1 \mathrm{~h}$ after feeding (cold tap water was used to mix the feeds).

The viscosity of a meal containing guar gum develops over a period of time as the guar gum hydrates and this depends on many factors. The viscosity of gastric digesta was measured several months later after storage in a freezer. Freezing itself does not affect viscosity but the viscosity of the digesta may increase whilst freezing and thawing are taking place since the meal was fed before its maximum viscosity was reached. Ideally, viscosity should have been measured on the samples of gastric digesta as soon as they were collected but this was not practical since the instrument had to be kept several miles from the animal house. 
As already mentioned, the addition of guar gum to the diet greatly increased the viscosity of the meal consumed. Unfortunately evacuated digesta was only kept separately from the rinses in weeks 3 and 4 of this experiment so no statistical analysis on the viscosity measurements of undiluted gastric digesta was possible. However, some interesting points were noted. The rapid fall in viscosity of the meals with guar gum $30 \mathrm{~min}$ after consumption was due in part to dilution with gastric secretions and outflow into the duodenum of a substantial part of the gastric contents. This effect was unlikely to be due to the $\mathrm{pH}$ of the gastric contents as the viscosities of guar gum solutions do not vary over a wide $\mathrm{pH}$ range. The viscosity of the digesta was the same 30 and 60 min after feeding, even though gastric secretion, emptying and dilution were occurring. This may be explained by the fact that the meal was fed before its time of maximum viscosity was reached. However, viscosity subsequently decreased, probably because of the large volume of secretions and the emptying of much of the digesta into the small intestine.

In the only (published) study on the effect of guar gum on the viscosity of digesta, Blackburn \& Johnson (1981) examined the liquid fractions of digesta in rats. Their semi-purified control diet and control $+3 \mathrm{~g}$ guar gum $/ \mathrm{kg}$ diet produced stomach contents of 'a watery consistency'. However, diets containing 10 and $20 \mathrm{~g}$ guar gum $/ \mathrm{kg}$ yielded stomach contents in the form of a solid mass, with a sticky exterior but almost dry interior, from which no liquid could be separated by centrifugation. Clearly, viscosity measurements could not be made under these conditions. Such measurements were possible in the present study because a large volume of water was thoroughly mixed with the diet before feeding, leading to gastric digesta in which the guar gum, as well as the other dietary components, were more or less fully hydrated. By contrast no mention was made of water provision by Blackburn \& Johnson (1981): the diet was fed as a dry powder. Blackburn \& Johnson (1981) also found that addition of guar gum to the diet at all levels increased the apparent viscosity of small-intestinal contents relative to the control, the increase being proportional to the amount of guar gum ingested. In studies on two pigs (A. L. Rainbird, unpublished results) killed $4 \mathrm{~h}$ after consuming a semi-purified diet without or with guar gum, the viscosity of the small intestinal contents was higher in the latter animal even in the terminal ileum.

Although the rate of emptying of digesta was reduced by the addition of guar gum to the diet, no differences in the emptying of DM or of total glucose were seen. This suggests that the main effects of guar gum in reducing postprandial hyperglycaemia are mediated by mechanisms other than modifications of gastric emptying.

The authors would like to thank Dr I. E. Sambrook for surgery, Mr A. R. Jones and his staff for care of the experimental animals, Mr H. A. Smith for technical assistance and Mrs R. J. Elliott for advice on the design of the experiments and on the statistical analysis of results. A.L.R. gratefully acknowledges receipt of an Agricultural Research Council postgraduate research studentship. The guar gum was kindly donated by $\mathrm{Mr}$ R. M.W. Hopkins of Meyhall Chemical (UK) Ltd.

\section{REFERENCES}

Barber, R. S., Braude, R., Mitchell, K. G. \& Pittman, R. J. (1972). Animal Production 14, 199-208.

Blackburn, N. A. \& Johnson, I. T. (1981). British Journal of Nutrition 46, 239-246.

Blackburn, N. A., Redfern J. S., Jarjis, H., Holgate, A. M., Hanning, I., Scarpello, J. H. B., Johnson, I. T. \& Read,

N. W. (1984). Clinical Science 66, 329-336.

Braude, R., Fulford, R. J. \& Low, A. G. (1976). British Journal of Nutrition 36, 497-510.

Cuber, J.-C. \& Laplace, J.-P. (1979). Annales de Biologie Animale Biochimie Biophysique 19, 899-905.

Cuber, J.-C., Laplace, J.-P. \& Villiers, P. A. (1980). Reproduction, Nutrition, Developpement 20, 1161-1172.

Daumerie, C. \& Henquin, J.-C. (1982). Diabete et Métabolisme 8, 1-5.

Fordtran, J. S. \& Walsh, J. H. (1973). Journal of Clinical Investigation 52, 645-657.

Heading, R. C., Tothill, P., McLouglin, G. P. \& Shearman, D. J. C. (1976). Gastroenterology 71, 45-50. 
Holt, S., Heading, R. C., Carter, D. C., Prescott, L. F. \& Tothill, P. (1979). Lancet i, 636-639.

Hunt, J. N. \& Knox, M. T. (1968). Journal of Physiology 104, 327-336.

Jarjis, H. A., Blackburn, N. A., Redfern, J. S. \& Read, N. W. (1984), British Journal of Nutrition 51, 371-378.

Jenkins, D. J. A. \& Wolever, T. M. S. (1981). Proceedings of the Nutrition Society 40, 227-235.

Jenkins, D. J. A., Wolever, T. M. S., Bacon, S., Nineham, R., Lees, R., Rowden, R., Love, M. \& Hockaday, T. D. R. (1980). American Journal of Clinical Nutrition 33, 1729-1733.

Jenkins, D. J. A., Wolever, T. M. S., Leeds, A. R., Gassull, M. A., Haisman, P., Dilawari, J., Goff, D. V., Metz, G. L. \& Alberti, K. G. M. M. (1978). British Medical Journal i, 1392-1394.

Kvasnitskii, A. V. (1951). Voprosy Fiziologii Pishchevarenija u Svinei. Moscow: Sel'khozgiz.

Lawrence, T. L. J. (1970). Animal Production 12, 151-163.

Leeds, A. R., Bolster, N. R., Andrews, R. \& Truswell, A. S. (1979). Proceedings of the Nutrition Society 38, 44A.

Leeds, A. R., Kang, S. S., Low, A. G. \& Sambrook, I. E. (1980). Proceedings of the Nutrition Society 39, 44A.

Low, A. G. (1974). Observations on the digestion of proteins by the growing pig. PhD Thesis, University of Reading.

Low, A. G., Pittman, R. I. \& Elliott, R. J. (1985). British Joumal of Nutrition 54, 437-447.

Low, A. G. \& Rainbird, A. L. (1984). British Journal of Nutrition 52, 499-505.

Low, A. G. \& Zebrowska, T. (1977). British Journal of Nutrition 38, $145-147$.

Malagelada, J.-R., Longstreth, G. R., Summerskill, W. H. J. \& Go, V. L. W. (1976). Gastroenterology 70, $203-210$.

Rainbird, A. L. (1983). Studies on the physiological action of dietary fibre in the stomach and small intestine of growing pigs. PhD Thesis, University of Reading.

Rainbird, A. L., Low, A. G. \& Sambrook, I. E. (1983). Proceedings of the Nutrition Society 42, 24 A.

Rainbird, A. L., Low, A. G. \& Zebrowska, T. (1984). British Journal of Nutrition 52, 489498.

Sambrook, I. E. \& Rainbird, A. L. (1985). British Journal of Nutrition 54, 27-35.

Simpson, H. C. R. (1981). Proceedings of the Nutrition Society 40, 219-225.

Wilmshurst, P. \& Crawley, J. C. W. (1980). British Journal of Nutrition 44, 1-6.

Zebrowska, T. \& Buraczewska, L. (1972). Roczniki Nauk Rolniczych, ser. B, 94, part 1, 81-96. 